\title{
TNF- $\alpha$ is a critical negative regulator of type 1 immune activation during intracellular bacterial infection
}

\author{
Anna Zganiacz, ${ }^{1}$ Michael Santosuosso, ${ }^{1}$ Jun Wang, ${ }^{1}$ Tony Yang, ${ }^{1}$ Lihao Chen, ${ }^{1}$ \\ Maria Anzulovic, ${ }^{1}$ Scott Alexander, ${ }^{1}$ Brigitte Gicquel, ${ }^{2}$ Yonghong Wan, ${ }^{1}$ \\ Jonathan Bramson, ${ }^{1}$ Mark Inman, ${ }^{1}$ and Zhou Xing ${ }^{1}$ \\ ${ }^{1}$ Infectious Diseases Division, Centre for Gene Therapeutics, and Department of Pathology and Molecular Medicine, \\ McMaster University, Hamilton, Ontario, Canada \\ ${ }^{2}$ Unité de Génétique Mycobactérienne, Institut Pasteur, Paris, France
}

\begin{abstract}
TNF- $\alpha$ has long been regarded as a proimmune cytokine involved in antimicrobial type 1 immunity. However, the precise role of TNF- $\alpha$ in antimicrobial type 1 immunity remains poorly understood. We found that $\mathrm{TNF}-\alpha$-deficient ( $\mathrm{TNF}^{-/-}$) mice quickly succumbed to respiratory failure following lung infection with replication-competent mycobacteria, because of apoptosis and necrosis of granuloma and lung structure. Tissue destruction was a result of an uncontrolled type 1 immune syndrome characterized by expansion of activated CD4 and CD8 T cells, increased frequency of antigen-specific T cells, and overproduction of IFN- $\gamma$ and IL-12. Depletion of CD4 and CD8 T cells decreased IFN- $\gamma$ levels, prevented granuloma and tissue necrosis, and prolonged the survival of $\mathrm{TNF}^{-/-}$hosts. Early reconstitution of TNF- $\alpha$ by gene transfer reduced the frequency of antigen-specific $T$ cells and improved survival. TNF- $\alpha$ controlled type 1 immune activation at least in part by suppressing $\mathrm{T}$ cell proliferation, and this suppression involved both TNF receptor $\mathrm{p} 55$ and TNF receptor $\mathrm{p} 75$. Heightened type 1 immune activation also occurred in $\mathrm{TNF}^{-/-}$mice treated with dead mycobacteria, live replication-deficient mycobacteria, or mycobacterial cell wall components. Our study thus identifies TNF- $\alpha$ as a type 1 immunoregulatory cytokine whose primary role, different from those of other type 1 cytokines, is to keep an otherwise detrimental type 1 immune response in check.
\end{abstract}

J. Clin. Invest. 113:401-413 (2004). doi:10.1172/JCI200418991.

\section{Introduction}

TNF- $\alpha$ possesses multifunctional activities and is one of the most important proinflammatory and proimmune cytokines (1). TNF- $\alpha$ was initially identified as a major cause of toxic syndromes seen in endotoxic sepsis. This cytokine is also believed to play an important pathogenic role in type 1 autoimmune diseases (1). Thus, therapeutic modalities based on anti-TNF- $\alpha$ have been developed to treat these conditions (2). On the other hand, TNF- $\alpha$ is also involved in type 1 cell-mediated immune responses to intracellular pathogens such as mycobacteria (3). Indeed, human subjects undergoing anti-TNF- $\alpha$ therapies experienced a dramatically increased incidence of reactivation of lung Mycobacteri-

Received for publication May 21, 2003, and accepted in revised form December 2, 2003.

Address correspondence to: Zhou Xing, Room 4H19, Health Sciences Center, Department of Pathology and Molecular Medicine, McMaster University, 1200 Main Street West, Hamilton, Ontario L8N 3Z5, Canada.

Phone: (905) 525-9140 ext. 22471; Fax: (905) 522-6750;

E-mail:xingz@mcmaster.ca.

Conflict of interest: The authors have declared that no conflict of interest exists.

Nonstandard abbreviations used: Mycobacterium tuberculosis (M.tb); bacille Calmette-Guérin (BCG); replicable M. bovis BCG (rBCG); TNF receptor $\mathrm{p} 55$ (TNFRp55); TNF receptor $\mathrm{p} 75$ (TNFRp75); C57BL/6 WT (B6-WT); bronchoalveolar lavage (BAL); M.tb culture-filtrate proteins (M.tb CF); dead M. bovis BCG (dBCG); auxotrophic M. bovis BCG (auBCG). um tuberculosis (M.tb) infection (4). Furthermore, a number of experimental studies have demonstrated that hosts with a deficiency in TNF- $\alpha$ or its receptors are susceptible to infection caused by mycobacteria including Mycobacterium bovis bacille Calmette-Guérin (BCG) (5-12). While the reasons underlying the death of these hosts still remain speculative, necrosis of tissue granulomas and heightened infection are observed frequently. Thus, all of the evidence together points to the requirement of TNF- $\alpha$ for host defense against intracellular pathogens. However, the precise role of TNF- $\alpha$ in antimicrobial type 1 immunity has remained poorly defined. In particular, little is known about whether TNF- $\alpha$ is involved in the regulation of type $1 \mathrm{~T}$ cell activation, how the function of TNF- $\alpha$ is related to maintenance of macrophage granuloma, and what is the relationship among $\mathrm{T}$ cell activation, granuloma integrity, and infection and death of the host. The importance of solving these issues is further highlighted by recent clinical and experimental findings that abrogation of TNF- $\alpha$ unexpectedly worsened a number of type 1 autoimmune conditions (13-17).

In this study, we have observed that TNF- $\alpha$-deficient $\left(\mathrm{TNF}^{-/-}\right)$mice rapidly succumbed to respiratory failure after lung infection by replicable M. bovis BCG (rBCG). These mice suffered a severe type 1 immune syndrome characterized by uncontrolled expansion of activated CD4 and CD8 T cells, increased frequency of mycobacterium-specific $\mathrm{T}$ cells, heightened local and systemic 
levels of type 1 cytokines IFN- $\gamma$ and IL-12, and disintegration of granuloma and lung structure. Depletion of CD4 and CD8 T cells resulted in decreased IFN- $\gamma$ levels, preserved macrophage granuloma, and prolonged the survival of infected $\mathrm{TNF}^{-/-}$hosts. A higher level of type 1 immune activation also ensued in $\mathrm{TNF}^{-/-}$hosts following treatment with heat-inactivated BCG or CFA, or infection with a replication-deficient auxotrophic strain of live M. bovis BCG bacilli. By using both in vitro and in vivo approaches, we have obtained evidence to suggest that TNF- $\alpha$ controls type 1 immune activation at least in part by suppressing $\mathrm{T}$ cell proliferation. Our study thus reveals that TNF- $\alpha$ is a critical negative regulator that controls the level of type 1 immune activation by restricting the number and activation of $\mathrm{T}$ cells during intracellular mycobacterial infection. Removal of this regulator results in an uncontrolled type 1 immune syndrome that is detrimental, rather than beneficial, to the host. Thus, rather than the usual mechanisms based on immune depression, our findings present a mechanism based on immune overactivation that leads to increased host susceptibility to intracellular bacterial infection. Our findings also call for caution in the use of anti-TNF- $\alpha$ therapeutics for the treatment of type 1 immune conditions including tuberculosis, autoimmune diseases, and allograft rejection.

\section{Methods}

Mice. Breeding pairs of C57BL/6 TNF- $\alpha$ gene-deficient $\left(\mathrm{TNF}^{-/-}\right)$mice were purchased from The Jackson Laboratory (Bar Harbor, Maine, USA). These mice were bred in our central animal facility under level A specific pathogen-free conditions. Breeding pairs of C57BL/ 6 TNF receptor $\mathrm{p} 55^{-/-}\left(\right.$TNFRp55 $\left.5^{--}\right)$mice were originally provided by Tak Mak (Ontario Cancer Institute and University of Toronto, Toronto, Ontario, Canada) (18). C57BL/6 WT (B6-WT) mice (Harlan Sprague Dawley Inc., Indianapolis, Indiana, USA) were housed under level B specific pathogen-free conditions until use. After infection, all mice were kept in autoclaved cages with autoclaved bedding, food, water, and microfilter lids in a biohazard level B facility. All experiments performed were in accordance with the guidelines of the Animal Research Ethics Board of McMaster University. Mycobacteria, viral cytokine gene transfer vectors, mycobacterial antigens, and antibodies. Live rBCG was originally obtained from Connaught Laboratories Ltd. (North York, Ontario, Canada). It was grown in Middlebrook 7H9 broth (Difco, Detroit, Michigan, USA) supplemented with Middlebrook OADC enrichment (GIBCO BRL, Invitrogen Corp., Gaithersburg, Maryland, USA), $0.002 \%$ glycerol, and $0.05 \%$ Tween-80. A strain of live, replication-deficient auxotrophic BCG was provided by Brigitte Gicquel (Institut Pasteur). This strain of BCG was amplified in $7 \mathrm{H} 9$ media containing kanamycin and hypoxanthine (19). Dead BCG was generated by heat inactivation of live replicable BCG at $80^{\circ} \mathrm{C}$ for $20 \mathrm{~min}$ utes, and the loss of viability was verified by colony assay. A replication-deficient adenoviral vector express- ing murine TNF- $\alpha$ (AdTNF) was previously constructed in our center (20). This virus has its E1 and E3 genomic regions partially deleted but remains fully infectious. As control, a replication-deficient adenoviral vector that does not contain cytokine transgene was used (Addl) (21, 22). Rat anti-mouse mAb's GK1.5 and 2.43 were produced in SCID mice and used to deplete CD4 and CD8 T cells, respectively. Rabbit anti-murine TNF- $\alpha$ serum was a kind gift from Steve Kunkel (University of Michigan, Ann Arbor, Michigan, USA). Normal rabbit serum was used as control. Mycobacterial antigens used in this study were M.tb culture-filtrate proteins $(M . t b \mathrm{CF})$ or M.tb cell wall lysates provided by Colorado State University (Fort Collins, Colorado, USA) under support by an NIH contract (NO1-AI-75320).

Mycobacterial infection and treatment with heat-inactivated mycobacteria or CFA. Pulmonary mycobacterial infection was elicited via the airway as previously described (22-26). Prior to infection, M. bovis BCG stock solution was diluted in PBS, and the preparation was sonicated to ensure proper dispersion of mycobacteria. Mice were infected by intratracheal instillation of BCG at a dose of $5 \times 10^{5} \mathrm{CFUs}$ in a total volume of $40 \mu \mathrm{l}$ per mouse. In the cases of auxotrophic BCG and heat-inactivated BCG, doses of $6 \times 10^{6}$ and $6 \times 10^{7} \mathrm{CFUs}$ per mouse, respective$1 y$, were intratracheally delivered. For intravenous infection with auxotrophic BCG, a dose of $5 \times 10^{7} \mathrm{CFUs}$ per mouse was injected. A colony assay was performed to assess the level of infection using tissue homogenates as previously described (22-26). For replication-competent BCG, Middlebrook 7H10 agar containing OADC enrichment (Difco) was used, and for auxotrophic BCG, Middlebrook 7H10 agar containing kanamycin and hypoxanthine (19) was used. Plates were incubated at $37^{\circ} \mathrm{C}$, and colonies were counted at days 11-13 under a dissecting microscope. A dose of $250 \mu \mathrm{g}$ of CFA (SigmaAldrich, St. Louis, Missouri, USA) was injected intraperitoneally into mice.

In vivo TNF- $\alpha$ reconstitution by gene transfer. In some experiments, at the time of mycobacterial infection, AdTNF or the control vector (Addl) was delivered intranasally and intramuscularly into $\mathrm{TNF}^{-/}$mice $(22$, 27-29). A dose of $2 \times 10^{8}$ PFUs of gene transfer vector was intranasally delivered in a total of $30 \mu \mathrm{l}$ to the nostril. For intramuscular delivery, a dose of $5 \times 10^{7} \mathrm{PFUs}$ of gene vector was injected into the muscle of the hind leg. We have previously demonstrated that intranasal gene transfer renders transgene expression primarily in airway epithelial cells and macrophages for a period of 8-12 days $(22,27)$, and that following intramuscular gene transfer, transgene expression is localized to the muscle of the injection site with transgene protein actively released into the bloodstream for 10-12 days (28).

In vivo CD4 and CD8 T cell depletion. Groups of $\mathrm{TNF}^{-1}$ mice were first infected intratracheally with live $M$. bovis BCG. At days 22, 28, 35, and 44 after infection, they were injected intraperitoneally with anti-CD4 $\mathrm{mAb}$, anti-CD8 mAb, or both (250 $\mathrm{g}$ g per dose). At day 37 , a group of mice was sacrificed, and the lungs and spleen 
were taken for FACS analysis, mycobacterial-colony assay, and histopathologic examination. Depletion of both CD4 and CD8 T cells was verified by FACS analysis of splenocytes and was found to be greater than $99 \%$. The rest of the mice were monitored for mortality. Mice treated with normal rat IgG antibody were set up in parallel as controls.

Bronchoalveolar lavage, tissue histopathology, and immunoperoxidase staining for identification of apoptosis. Peripheral blood was taken retro-orbitally from mice for serum preparation, and bronchoalveolar lavage (BAL) was carried out on the lung by a standard procedure previously described (22-26). Sera and BAL supernatants were stored at $-20^{\circ} \mathrm{C}$ until cytokine assay. The lung and liver tissues were fixed in $10 \%$ formalin. Tissue sections were stained with $\mathrm{H} \& \mathrm{E}$ for conventional histopathologic examination. Formalin-fixed and paraffin-embedded tissue sections were also processed and stained for apoptotic cells using an ApopTag Plus in situ apoptosis detection kit (Intergen Co., Purchase, New York, USA). This kit allows specific detection of apoptotic, but not necrotic, cells by labeling DNA cleavage and chromatin condensation associated with apoptosis. After immunostaining, tissue sections were counterstained with methyl green.

Ex vivo stimulation of total lymphocytes and purified CD4 $T$ cells. Total splenocytes or thoracic lymph node cells were isolated as previously described (22-26). These cells were cultured for 72 hours with or without M.tb $\mathrm{CF}$. In some cases, CD4 T cells were purified from whole-splenocyte preparations using mouse T cell CD4 subset purification column kits (R\&D Systems Inc., Minneapolis, Minnesota, USA). Purified T cells were stimulated with mycobacterium-infected alveolar macrophages (APC) for 72 hours. For APC preparation, alveolar macrophages isolated from naive $\mathrm{C} 57 \mathrm{BL} / 6$ and $\mathrm{TNF}^{-/-}$mice were seeded into 96-well plates (4,000 cells per well) and infected with 20 CFUs per cell of live BCG overnight prior to coculture with $\mathrm{T}$ cells.

Frequency of mycobacterium-specific $T$ cells by ELISPOT assay. Isolated whole splenocytes, lymph node cells, or purified CD4 T cells $\left(0.4 \times 10^{6}\right.$ per well $)$ were seeded into a 96-well PVDF microplate (Millipore Corp., Bedford, Massachusetts, USA) precoated overnight with a mouse IFN- $\gamma$ capture antibody (R\&D Systems Inc.; 1:60 dilution). Cells were incubated for 24 hours with or without stimulation by $M . t b$ CF or phytohemagglutinin. The plate was then developed by the standardized streptavidin-conjugated alkaline phosphatase and chromogen method (R\&D Systems Inc.). The number of IFN- $\gamma$-releasing cells was determined under a dissecting microscope.

FACS analysis of $T$ cell phenotypes and intracellular staining of IFN- $\gamma$-secreting $T$ cells. Immunostaining and FACS analysis procedures were carried out as previously described $(23,25,26)$. Both BAL cells and thoracic lymph node cells were subjected to flow cytometric analysis. The phenotypes of $\mathrm{T}$ cells were examined using mAb's against murine CD3 (hamster; FITC label), CD4 (rat; biotin), CD8 (rat; biotin), and CD69 (hamster; phyco- erythrin). Data were collected by FACScan (Becton Dickinson Immunocytometry Systems, Sunnyvale, California, USA) with gating on the lymphocyte region, and analyzed using PC-Lysis software (Becton, Dickinson and Co., San Jose, California, USA). For intracellular staining of IFN- $\gamma$, isolated total splenocytes were cultured for 6 hours in the presence of brefeldin (GolgiPlug) with or without crude mycobacterial antigens. Cells were then processed for staining with mAb's for CD3 (hamster; CyChrome label), CD4 (rat; FITC), or CD8 (rat; FITC) and a phycoerythrin-conjugated anti-murine IFN- $\gamma$ antibody (rat; phycoerythrin). Rat IgG1 was used as an isotype control. Data collection and analysis were carried out as described above. All of the reagents used for FACS and intracellular staining were purchased from BD Pharmingen (San Diego, California, USA).

In vitro and in vivo Tcell proliferation assays. ${ }^{3} \mathrm{H}$-thymidine incorporation assay was used to calibrate lymphocyte proliferation in vitro as previously described (29). For in vivo T cell proliferation assay, B6-WT and $\mathrm{TNF}^{-/-}$mice were intratracheally infected with live replicable BCG for 7 days, and splenic CD4 T cells were isolated. CD4 T cells were then labeled with CFSE (Molecular Probes Inc., Eugene, Oregon, USA). Briefly, cells were resuspended in PBS $/ 10 \%$ FBS at $15 \times 10^{6}$ cells per milliliter. CFSE was added to cells at a final concentration of $5 \mu \mathrm{M}$, and cells were incubated at room temperature for 5 minutes. Cells were then washed three times with $10 \mathrm{vol}$ of PBS/10\% FBS, resuspended in $200 \mu \mathrm{l}$ RPMI, and adoptively transferred via tail vein injection into naive $\mathrm{B} 6-\mathrm{WT}$ and $\mathrm{TNF}^{-/}$mice whose lymphocytes had been eliminated 2 days earlier by sublethal $\gamma$-irradiation (6 Gy) (30). Eight days after T cell transfer, the whole splenocytes were isolated and immunostained with an anti-CD4 antibody. FACS analysis was carried out by gating on CD4- and CFSEpositive $\mathrm{T}$ cells.

Measurement of cytokines by ELISA. The concentration of IFN- $\gamma$, IL-12, TNF- $\alpha$, IL-10, and IL-2 in BAL, sera, or culture supernatant was measured by ELISA kits (R\&D Systems Inc.). The sensitivity of detection for all of these kits was less than or equal to $5-10 \mathrm{pg} / \mathrm{ml}$.

Measurement of respiratory and hepatic functions. The percentage of oxygen saturation of hemoglobin in the arterial blood was measured at various times after infection by a veterinary oximeter with the probe placed on the well-shaved hind leg, and it was used as an index of oxygen pressure in blood and respiratory function (31). The level of alanine and aspartate aminotransferases in serum was measured in an automated analyzer as an index of liver injury (32).

Data analysis. Whenever applicable, the difference comparison was made using a Student $t$ test. The difference was considered statistically significant at $P \leq 0.05$.

\section{Results}

$T N F^{-1-}$ hosts succumbed to respiratory failure within a narrow window of time after infection by replicable mycobacteria. Following pulmonary mycobacterial infection by live rBCG, 

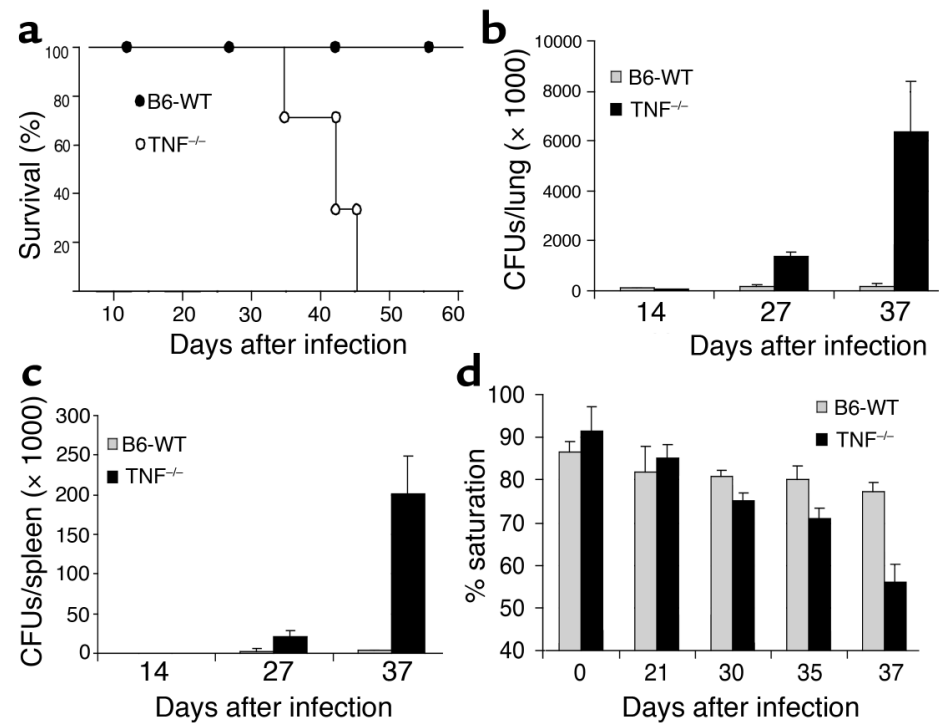

Figure 1

(a) Mortality of $\mathrm{TNF}^{-/-}$mice following infection by rBCG. Both B6-WT and $\mathrm{TNF}^{-1-}$ mice were infected intratracheally with $\mathrm{rBCG}$, and the mortality of the mice was monitored thereafter. Results are from 15-20 mice per group, representative of more than two experiments. ( $\mathbf{b}$ and $\mathbf{c}$ ) Tissue level of mycobacterial infection. Infected B6-WT and $\mathrm{TNF}^{-1-}$ mice were sacrificed at days 14, 27, and 37 , and their lungs (b) and spleens (c) were homogenized and evaluated by using a colony enumeration assay. Results are expressed as mean \pm SEM from 6-12 mice per group per time. The difference between B6-WT and $\mathrm{TNF}^{-1-}$ at both days 27 and 37 is statistically very significant $(P \leq 0.01)$. (d) Hemoglobin oxygen saturation in the peripheral blood over the course of pulmonary mycobacterial infection. At various time points, the percentage of oxygen saturation of hemoglobin was measured on live mice by using a veterinary oximeter. Results are expressed as mean \pm SEM from 5-10 mice per group per time point.

B6-WT mice remained healthy throughout the study. $\mathrm{TNF}^{-/-}$mice remained healthy until day 30 after infection and became ill around day 35 . All $\mathrm{TNF}^{-/-}$mice died around day 40 (Figure 1a). We further examined the level of infection in the tissue. There was no difference between $\mathrm{B} 6-\mathrm{WT}$ and $\mathrm{TNF}^{-/-}$mice in the number of bacilli in both the lung $(96,937 \pm 19,895$ vs. $55,375 \pm 15,046$ CFUs per lung, respectively) and the spleen (50 \pm 22 vs. $135 \pm 45$ CFUs per spleen, respectively) by day 14 after infection (Figure 1, b and c). However, the level of infection in $\mathrm{TNF}^{-/-}$mice was much higher at days 27 and 37 prior to the death of these mice (Figure 1, b and c). Upon comparison with our previous study, which used SCID mice, we found that SCID hosts endured a much higher level of BCG infection and succumbed much later than $\mathrm{TNF}^{-/-}$mice (22). Furthermore, following M.tb infection, $\mathrm{TNF}^{-1-}$ mice were also reported to die by 35 days (10), a time similar to that when our $\mathrm{TNF}^{-/-}$mice succumbed to M. bovis BCG infection. Since M.tb is much more virulent than BCG, these findings together suggest that $\mathrm{TNF}^{-/-}$hosts did not die of infection.

Thus, in a separate experiment, we examined the respiratory function of both $\mathrm{B} 6-\mathrm{WT}$ and $\mathrm{TNF}^{-/-}$mice at various time points after infection by measuring the percentage saturation of hemoglobin with oxygen in the peripheral blood. While a slight decrease in percentage saturation in B6-WT mice remained relatively steady throughout the experiment, a significant drop at day 35 and a decrease of more than $40 \%$ at day 37 were demonstrated in $\mathrm{TNF}^{-/-}$mice, indicating respiratory failure (Figure 1d). Examination of two aminotransferases (alanine aminotransferase and aspartate aminotransferase) in the peripheral blood suggested no significant hepatic injury in these mice (not shown).

Lung-granuloma formation, apoptosis, and necrosis in $\mathrm{TNF}^{-/}$hosts. We next examined the histopathologic basis of respiratory failure. The overall granuloma formation in $\mathrm{TNF}^{-/-}$ lung was not impaired, although the granuloma appeared a bit smaller at earlier times. However, many macrophages within granulomas were found to be fragmented at day 27 , which suggests apoptosis (Figure 2f), in sharp contrast to B6-WT control granuloma (Figure 2a). By day 37, microscopically, at least onethird of the area of all TNF-/- lungs was occupied by massive necrotic areas ("caseous necrosis") with destruction of normal lung structure (Figure 2, h and i). To verify apoptosis, an ApopTag kit was used to specifically label apoptotic cells in the tissue. While only a very small number of macrophages in B6-WT granuloma stained positive for apoptosis at various times (Figure 2, b and e), a large number of apoptotic cells were found in the lung of $\mathrm{TNF}^{-/}$- mice at day 27 (Figure $2 \mathrm{~g}$ ) $(4.8 \pm 1.1 \mathrm{per}$ granuloma in B6-WT mouse lung vs. $61.6 \pm 14$ per granuloma in $\mathrm{TNF}^{-/-}$mouse lung, $P=0.000001$ ). By day 37 , many apoptotic cells were located throughout necrotic areas, and lung structural cells at the periphery of necrosis also stained positive for apoptosis (Figure $2 \mathrm{j}$ ). In comparison with the lung, the liver of $\mathrm{TNF}^{-/}$ mice contained small discrete granulomas and inflammatory infiltrates in the portal and perivascular areas, but there was little evidence of extensive apoptosis and necrosis (data not shown). These findings together indicate that the lung represents a primary site of organ failure caused by apoptosis and massive tissue destruction. Since such an extent of macrophage apoptosis and granuloma necrosis was never seen in the lung of other immune-compromised mouse strains susceptible to mycobacterial infection, including IL-12-/- (23) and SCID mice (22), it most likely resulted from mechanisms different from infection.

Overproduction of type 1 cytokines in the lung and peripheral blood of $\mathrm{TNF}^{-/}$hosts. To begin the investigation of the mechanisms underlying tissue destruction in $\mathrm{TNF}^{-/}$- hosts during $\mathrm{rBCG}$ infection, we measured the level of type 1 immune cytokines in vivo. At day 14 after infection, the level of IFN- $\gamma$ and IL-12 was similar between B6-WT and $\mathrm{TNF}^{-/-}$mice in both the lung (Figure 3 , a and b) and peripheral blood (not shown). How- 

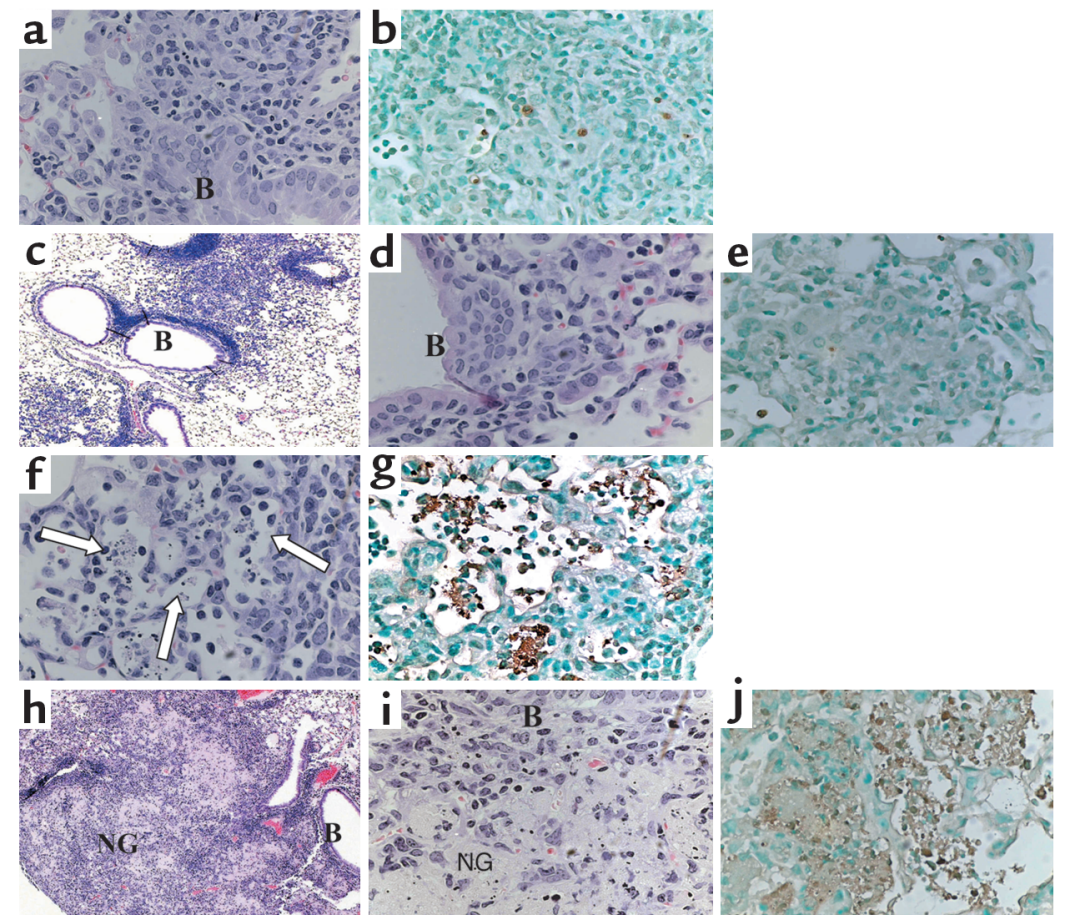

\section{Figure 2}

Histopathologic changes in the lungs of B6-WT and $\mathrm{TNF}^{-1-}$ mice following pulmonary $\mathrm{rBCG}$ mycobacterial infection. B6-WT (a-e) and $\mathrm{TNF}^{-/-}$mice $(\mathbf{f}-\mathbf{j})$ were sacrificed at days $27(\mathbf{a}$, $\mathbf{b}, \mathbf{f}, \mathbf{g})$ and $37(\mathbf{c}-\mathbf{e}, \mathbf{h}-\mathbf{j})$. Their lung tissue sections were stained with $\mathrm{H} \& \mathrm{E}(\mathbf{a}, \mathbf{c}, \mathbf{d}, \mathbf{f}, \mathbf{h}, \mathbf{i})$ or were subject to ApopTag Plus immunostaining and methyl green counterstaining for identification of apoptosis ( $\mathbf{b}, \mathbf{e}, \mathbf{g}, \mathbf{j})$. B, bronchus; NG, necrotic granuloma. Arrows show apoptotic cells. These histomicrographs are representative of the lungs from at least three mice per group per time. Magnification, $\times 20(\mathbf{c}, \mathbf{h})$ and $\times 400(\mathbf{a}, \mathbf{b}, \mathbf{d}-\mathbf{f}, \mathbf{i}, \mathbf{j})$. ever, by days 27 and 37, the level of these cytokines in $\mathrm{TNF}^{-/}$hosts was much higher than in B6-WT mice (Figure 3, a and b). Compared with IL-12, the level of IFN- $\gamma$ was much more elevated in both the lung and peripheral blood. For instance, at days 27 and 37, $\mathrm{TNF}^{-/-}$lung contained 4 and 140 times as much IFN- $\gamma$, respectively, as did B6-WT lung.

Hyperreactive $C D 4$ and $C D 8$ T cell responses in the lung and lymphoid organs of $\mathrm{TNF}^{-1-}$ hosts. To investigate the cellular basis of overproduction of type 1 cytokines, particularly IFN- $\gamma$, in $\mathrm{TNF}^{-/-}$hosts, cellular and antigen-specific $\mathrm{T}$ cell IFN- $\gamma$ responses were examined following rBCG infection. At day 27 after infection, while the number of lung macrophages and neutrophils was similar between $\mathrm{B} 6-\mathrm{WT}$ and $\mathrm{TNF}^{-/-}$mice, the number of total lymphocytes was much greater in the lung of $\mathrm{TNF}^{-/-}$mice. By day 37, $\mathrm{TNF}^{-/-}$lung contained 32 times as many lymphocytes as that of B6-WT controls (not shown). The thoracic draining lymph nodes of $\mathrm{TNF}^{-/}$ mice contained ten times as many cells as those of B6-WT control mice. By flow cytometric analysis, these expanded lymphocytes were found to be primarily CD4 $\mathrm{T}$ cells, although the number of CD8 $\mathrm{T}$ cells was also markedly increased (Figure 3, c and d) and many of these $\mathrm{T}$ cells were activated, expressing lymphocyteactivation surface marker CD69.

Since markedly increased T cell numbers and IFN- $\gamma$ levels in $\mathrm{TNF}^{-/-}$mice suggest the overactivation of type 1 immune responses to mycobacterial infection and increased production of IFN- $\gamma$ by antigen-specific $\mathrm{T}$ cells, we examined the level of IFN- $\gamma$ production by lymphocytes of lymphoid organs upon mycobacterial antigen stimulation. There was relatively little antigen-recall IFN- $\gamma$ response by whole splenocytes of B6-WT mice at days 7 and 14 after infection (Figure 3e). In contrast, while the antigen-recall IFN- $\gamma$ response was very small in $\mathrm{TNF}^{-/}$mice at day 7 , such responses were already markedly higher in the splenocytes of $\mathrm{TNF}^{-/-}$mice by day 14 after infection $\left(717 \pm 78 \mathrm{pg} / \mathrm{ml}\right.$ in $\mathrm{TNF}^{-/}$mice vs. $86 \pm 6 \mathrm{pg} / \mathrm{ml}$ in B6-WT controls, $P=0.0006$ ) (Figure 3e). Since the level of infection was almost identical between B6-WT and $\mathrm{TNF}^{-/-}$mice at day 14 (Figure 1, b and c), these findings indicate that, firstly, an uncontrolled type $1 \mathrm{~T}$ cell activation occurred early in the course of immune responses to mycobacterial infection in $\mathrm{TNF}^{-/}$ hosts, and secondly, such heightened type 1 immune activation was not due to a higher infectious burden in these hosts. Such early heightened T cell activation continued to rise at an accelerated pace, and the magnitude of mycobacterial antigen-stimulated IFN- $\gamma$ responses in splenocytes was eight and ten times as much as in those of B6-WT controls at days 27 and 37, respectively (Figure $3 e)$. Antigen-stimulated IFN- $\gamma$ production by whole thoracic lymph node cells of $\mathrm{TNF}^{-/-}$mice was also many times higher (not shown). To examine the relative contribution of CD 4 and CD8 T cells to IFN- $\gamma$ production, the whole splenocytes were purified from $\mathrm{TNF}^{-/-}$mice at day 27 after infection and then cultured in the presence of mycobacterial antigens along with anti-CD4 or anti-CD8 mAb's or both. Depletion of CD4 T cells resulted in more than $90 \%$ reduction in IFN- $\gamma$ production, whereas CD8 T cell depletion caused only about $30 \%$ reduction (Figure 3f). Depletion of both CD4 and $\mathrm{CD} 8 \mathrm{~T}$ cells reduced IFN- $\gamma$ production by more than $90 \%$. These results suggest that CD4 $\mathrm{T}$ cells represent a major source of IFN- $\gamma$ production.

Increased frequency of antigen-specific type $1 \mathrm{CD} 4$ and $C D 8$ $T$ cells in $\mathrm{TNF}^{-/-}$mice. To investigate whether overpro- 
duction of IFN- $\gamma$ by T cells was at least in part due to an increased number of mycobacterial antigen-specific $\mathrm{T}$ cells, an ELISPOT assay was employed. In accord with the higher amounts of IFN- $\gamma$ measured in lymphocyte cultures of $\mathrm{TNF}^{-/-}$mice (Figure 3e), there were twice as many IFN- $\gamma$-releasing, mycobacterial antigen-specific cells in whole splenocytes at days 14 and 27 after infection (Figure 4, a and b). Significantly higher frequencies of antigen-specific $\mathrm{T}$ cells in $\mathrm{TNF}^{-/-}$mice were also verified by intracellular IFN- $\gamma$ staining techniques and FACS analysis (Table 1). B6-WT mice had a relatively small frequency of antigen-specific CD4 and CD8 T cells. In contrast, $\mathrm{TNF}^{-/-}$hosts had higher frequencies of antigen-specific CD4 and CD8 T cells. These findings suggest that heightened type $1 \mathrm{~T}$ cell activation that manifested in $\mathrm{TNF}^{-/-}$mice as early as 14 days after infection resulted at least partially from a greater number of antigen-specific $T$ cells, particularly $T h 1$ cells. That the magnitude of dramatically increased IFN- $\gamma$ production in lymphocytes by day 27 in $\mathrm{TNF}^{-/-}$mice cannot be explained solely by increased frequency of antigen-specific $\mathrm{T}$ cells suggests an increased IFN- $\gamma$-releasing capacity of T cells after day 14 after infection.

Early TNF- $\alpha$ reconstitution by gene transfer in $\mathrm{TNF}^{-1-}$ - hosts controls the number of antigen-specific type $1 \mathrm{~T}$ cells. To further investigate the requirement of TNF- $\alpha$ for control of the level of type 1 immune activation in the early course of mycobacterial infection, a replication-deficient adenoviral vector (AdTNF) was used to transfer the gene coding for murine TNF- $\alpha$ into $\mathrm{TNF}^{-/-}$mice. AdTNF was delivered both intranasally and intramuscularly to $\mathrm{TNF}^{-/-}$mice at the time of rBCG infection. We

\section{Figure 3}

(a) IL-12 levels in BAL fluids. (b) IFN- $\gamma$ levels in BAL fluids. These cytokines were measured by using ELISA kits. Results are expressed as mean \pm SEM from 5-9 mice per group per time point. The difference between B6-WT and $\mathrm{TNF}^{-/-}$at day 37 is statistically very significant $(P \leq 0.01)$ ( $\mathbf{a}$ and $\mathbf{b})$. ( $\mathbf{c}$ and $\mathbf{d}$ ) Immune phenotypes of T cells in the lung (c) and thoracic lymph nodes (LN) (d). Pooled cells from several mice per group were subject to FACS staining and analysis by the use of monoclonal antibodies for CD3, CD4, CD8, and CD69. T cell subsets were identified as those coexpressing CD3/CD4, CD3/CD8, CD3/CD4/CD69 and CD3/CD8/CD69. The numbers in the parentheses represent the fold increase in each subset of lymphocytes over B6-WT controls. (e) Antigen-specific IFN- $\gamma$ responses in whole lymphocytes of lymphoid organs. Total lymphocytes were isolated from pooled spleens of several mice per group at various time points after pulmonary rBCG mycobacterial infection and cultured with or without mycobacterial antigens (M.tb CF). Supernatants were measured for IFN- $\gamma$ by ELISA. Results are expressed as mean \pm SEM of triplicate wells, representative of 2-3 independent experiments. Differences between B6-WT and TNF-/- at days 14, 27 and 37 are all statistically very significant $(P \leq 0.01)$. (f) Relative contribution of CD4 and CD8 $T$ cells to antigen-specific IFN- $\gamma$ release. At day 27 , purified splenocytes were cultured with or without M.tb CF and control normal rat $\operatorname{lgG}$ (C.Ab), and anti-CD4 or anti-CD8 monoclonal antibody or both, and supernatants were measured for IFN- $\gamma$ release by ELISA. Results are expressed as mean \pm SEM from triplicate wells per time point or condition. The difference between C.Ab and antibody-treated cultures is statistically very significant $(P \leq 0.01)$. Ag, antigen. have previously shown that the gene transferred as such will render transgene expression for a period of 10-12 days in the lung and muscle (22, 27-29). As control, an empty adenoviral vector (Addl) was delivered to a group of $\mathrm{TNF}^{-/-}$mice in the same manner. Indeed, upon TNF- $\alpha$ gene transfer to $\mathrm{TNF}^{-/-}$mice, circulating levels of TNF- $\alpha$ were markedly raised (Table 2 ), and such TNF- $\alpha$ expression in $\mathrm{TNF}^{-/}$- hosts significantly decreased the frequency of mycobacterium-specific $\mathrm{T}$ cells in the spleen to a level similar to that in B6-WT controls (Figure 5 a). The amounts of IFN- $\gamma$ released by these cells were also correspondingly decreased (Figure $5 \mathrm{~b}$ ). Such transient TNF- $\alpha$ gene transfer at the time of infection also improved the survival of $\mathrm{TNF}^{-/-}$mice (not shown). These findings suggest an important role of TNF- $\alpha$ in governing the level of type 1 immune activation.

Depletion of CD4 and CD8 T cells prevented granuloma and tissue destruction and prolonged survival of infected $\mathrm{TNF}^{-1-}$ hosts. Thus far we have demonstrated that the death of infected $\mathrm{TNF}^{-/}$mice is associated with a type 1 immune syndrome, lung-tissue destruction, and respiratory failure, as a result of TNF- $\alpha$ deficiency. To directly demonstrate the causal relationship between the type 1 immune syndrome and mortality, we used mAb's to deplete CD4 and/or CD8 T cells in infected TNF-/- mice. Depletion of $\mathrm{T}$ cells markedly improved the survival of these mice (Figure 5c), and this was accompanied by markedly decreased levels of IFN- $\gamma$ in the lung and peripheral blood (Figure 5d; $107 \mathrm{pg} / \mathrm{ml}$ serum vs. $677 \mathrm{pg} / \mathrm{ml}$ serum
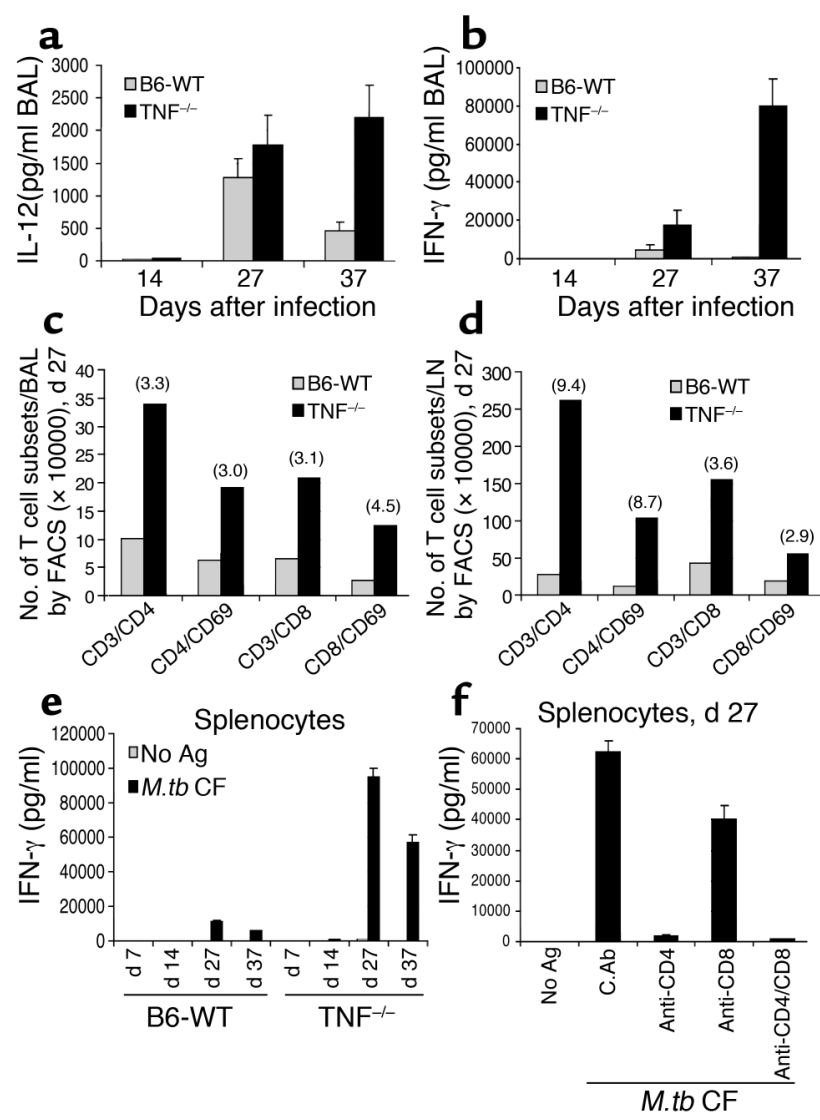

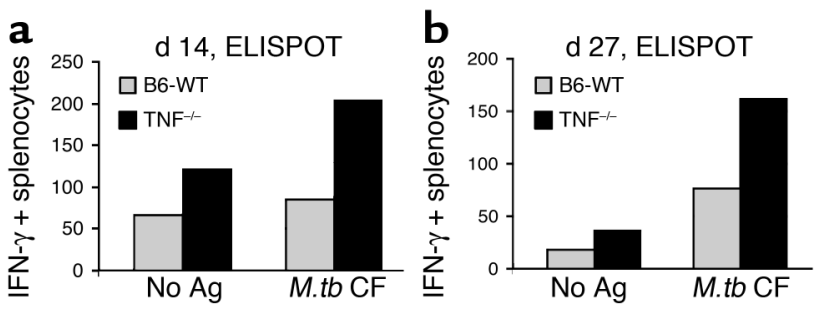

\section{Figure 4}

Increased frequency of antigen-specific, IFN- $\gamma$-releasing $\mathrm{T}$ cells in rBCG-infected TNF-/- hosts. (a) ELISPOT at day 14. (b) ELISPOT at day 27. At days 14 and 27, isolated total lymphocytes from spleens were cultured in the presence or absence of mycobacterial antigens (M.tb CF) and subject to Elispot assay to determine the relative frequency of mycobacterial antigen-specific $T$ cells. Results are expressed as the average number of antigen-specific $T$ cells per half million cells from duplicate wells per condition, representative of two independent experiments.

in the control group), decreased IFN- $\gamma$ release by splenocytes (not shown), the maintenance of granuloma integrity, and the prevention of tissue destruction (Figure 5 , e and $\mathrm{f}$ ). Of importance, compared with the level in controls, the level of mycobacterial infection in the lung and spleen of $\mathrm{TNF}^{-/}$mice was not significantly altered by $T$ cell depletion $\left(4.5 \times 10^{6} \pm 3.3 \times 10^{6} \mathrm{CFUs}\right.$ per lung vs. $6.3 \times 10^{6} \pm 2.0 \times 10^{6} \mathrm{CFUs}$ per lung in $\mathrm{TNF}^{-/}$controls). These findings suggest that, firstly, type $1 \mathrm{~T}$ cell activation, when uncontrolled, is a direct cause of granuloma disintegration and tissue destruction and subsequent organ failure; secondly, heightened mycobacterial infection in $\mathrm{TNF}^{-/}$- hosts is not the cause of quick death; and thirdly, TNF- $\alpha$ per se is not required for granuloma formation during mycobacterial infection.

Both TNFRp55 and TNFRp 75 played a role in controlling the level of type 1 immune activation. Since TNFRp55 is believed to mediate many biologic activities by TNF- $\alpha$, we investigated the contribution of TNFRp55-mediated and TNF receptor p75-mediated (TNFRp75-mediated) signaling to the control of type 1 immune activation in mycobacterial infection. At day 37, TNFRp55-mice infected with rBCG produced higher levels of IFN- $\gamma$ in the lung (Figure 6a) or in lymphocyte cultures compared with B6-WT controls (Figure 6b). However, this level of enhanced type 1 immune activation had little effect on the integrity of granuloma (Figure $6 c$ ), and the level of infection did not differ from that in WT controls (not shown). These findings suggest that TNFRp75 also plays a role in the regulation of type 1 immune activation. To investigate further, infected TNFRp55 mice were treated with anti-murine TNF- $\alpha$ polyclonal antibodies at weeks 1,2 , and 3 after infection and sacrificed at day 37 . We found that blockade of the engagement of the TNFRp75-mediated pathway in the absence of TNFRp55 led to further-enhanced type 1 immune activation both in the lung and in lymphoid cells (Figure 6, a and b). Such heightened type 1 immune activation, as a result of a lack of TNFRp55and TNFRp75-mediated signaling, was accompanied by macrophage apoptosis, granuloma disintegration (Figure 6d), and increased mycobacterial counts in the tissue (not shown) - changes reminiscent of those found in $\mathrm{TNF}^{-/-}$mice (Figure 2). These findings thus suggest that both TNFRp55 and TNFp75 are involved in the control of type 1 immune activation.

Heightened type 1 immune activation in $\mathrm{TNF}^{-1-}$ hosts treated with dead mycobacteria, live replication-deficient auxotrophic mycobacteria, or mycobacterial cell wall components. To further investigate the immune-suppressive role of TNF- $\alpha$, both B6-WT and $\mathrm{TNF}^{-/}$mice were treated with heat-inactivated (dead) M. bovis BCG (dBCG) or infected with an auxotrophic strain of M. bovis BCG (auBCG) that was rendered genetically incapable of replication because of a lack of the gene required for purine synthesis (19). This approach allowed us to investigate whether lack of TNF- $\alpha$ would still result in heightened levels of type 1 immune activation when the level of mycobacterial antigen or organism loads was similar in WT and $\mathrm{TNF}^{-/-}$hosts. Indeed, following lung inoculation of $\mathrm{dBCG}$, the level of IFN- $\gamma$ was higher in the lung of $\mathrm{TNF}^{-/-}$mice (Figure 7a). The splenocytes isolated from dBCG-treated $\mathrm{TNF}^{-/-}$mice at days 14 and 27 released much more IFN- $\gamma$ than those from their WT counterparts upon antigen stimulation (Figure 7, b and c). Reconstitution of TNF- $\alpha$ by adenovirus-mediated gene transfer markedly reduced such heightened IFN- $\gamma$ responses (Figure $7 b$ ). Qualitatively similarly enhanced type 1 immune activation was also observed in $\mathrm{TNF}^{-/}$mice following intravenous injection of dBCG (not shown). Using a different approach, mice were infected with live but replication-deficient auBCG. Following lung infection with auBCG, the frequency of IFN- $\gamma$-releasing splenocytes or CD4 T cells in $\mathrm{TNF}^{-/-}$hosts was higher than that in WT controls (not shown). Likewise, following intravenous infection with auBCG, splenocytes of $\mathrm{TNF}^{-/}$mice produced higher levels of IFN- $\gamma$ upon antigen stimulation, and concurrent in vivo TNF- $\alpha$ gene transfer inhibited such heightened responses (Figure 7d). In this model, the differential regulation of type 1 immune activation was independent of infection level, since the infection level did not differ among groups of B6-WT mice, $\mathrm{TNF}^{-} /-$ mice, and $\mathrm{TNF}^{-/-}$mice that received TNF- $\alpha$ gene transfer $(7,000-10,000$ CFUs per spleen by day 21 ; data not

\section{Table 1}

Increased frequency of antigen-specific IFN- $\gamma$-releasing CD4 and CD8 $T$ cells by intracellular cytokine staining

$\begin{array}{lcc} & \text { CD4 T cells } & \text { CD8 T cells } \\ \text { B6-WT } & 0.84 \%(0.51 \%) & 0.73 \%(0.56 \%) \\ \text { TNF }^{-/-} & 4.07 \%(1.29 \%) & 3.57 \%(1.84 \%)\end{array}$

At day 27, isolated total splenocytes were pooled and cultured for 6 hours in the presence of brefeldin with or without crude mycobacterial antigen stimulation (cBCG), and the cells were then subjected to intracellular IFN- $\gamma$ staining and FACS analysis in conjunction with the use of anti-CD3, -CD4, and -CD8 antibodies. The percentage represents the relative size of cell population that coexpresses both IFN- $\gamma$ and CD4 or CD8 (the level of unstimulated controls is in parentheses). 
Table 2

Circulating levels of TNF- $\alpha$ in TNF-/- mice after TNF- $\alpha$ gene transfer

\begin{tabular}{cccc}
\hline Day 1 & Day 3 & Day 5 & Day 8 \\
$45.55 \pm 26.6$ & $492.74 \pm 42.50$ & $520.65 \pm 55.28$ & $301.44 \pm 8.34$
\end{tabular}

The peripheral blood was collected and sera were prepared at days 1, 3, 5, and 8 after intranasal and intramuscular delivery of AdTNF. The level of circulating TNF- $\alpha$ was determined by ELISA. The results are expressed in $\mathrm{pg} / \mathrm{ml}$ as mean $\pm \mathrm{SEM}$ from three mice.

shown). To rule out that heightened type 1 immune activation in $\mathrm{TNF}^{-/-}$hosts is dependent on delayed clearance of phagocytosed whole mycobacterial organisms, mice were injected intraperitoneally with CFA containing mycobacterial cell wall components. Again, splenocytes of $\mathrm{TNF}^{-/-}$mice produced much higher levels of IFN- $\gamma$ upon antigen stimulation (Figure 7e). These results, in conjunction with the results obtained from the experiments using rBCG, thus indicate that it is TNF- $\alpha$ that is critically required for control of the level of type 1 immune activation upon exposure to replication-efficient, nonreplicable or dead mycobacteria, or mycobacterial cell wall components.

Mechanisms by which TNF- $\alpha$ controls type 1 immune activation. To investigate the potential mechanisms by which TNF- $\alpha$ controls type 1 immune activation, we first examined whether TNF- $\alpha$ did so by inducing anti- inflammatory cytokine IL-10. To this end we examined the level of IL-10 production both in the lung and by antigen-stimulated lymphocytes following rBCG infection. Rather than being lower, IL-10 levels in $\mathrm{TNF}^{-/-}$ mice were slightly higher than in B6-WT mice (not shown), suggesting that this cytokine's role is small. To examine whether TNF- $\alpha$ controls type 1 immune activation by directly suppressing T cell IFN- $\gamma$ release, splenocytes isolated from $\mathrm{TNF}^{-/-}$mice 27 days after rBCG infection were stimulated in vitro with mycobacterial antigen in the absence or presence of exogenously added TNF- $\alpha$. TNF- $\alpha$ had little effect on heightened IFN- $\gamma$ production, whether it was added concurrently with antigen (Figure 8a) or used to pretreat cells before antigen stimulation (not shown). In contrast, recombinant IL-10 as a positive control potently inhibited such responses (Figure 8a). These results suggest that TNF- $\alpha$ does not control type 1 immune activation by directly regulating IFN- $\gamma$ production in type $1 \mathrm{~T}$ cells.

To investigate the possibility that TNF- $\alpha$ controls type 1 immune activation by regulating the level of $\mathrm{T}$ cell proliferation, we examined mycobacterial antigen-stimulated proliferation of splenocytes isolated from dBCG- or auBCG-treated mice, using ${ }^{3} \mathrm{H}$-thymidine incorporation assay. We found that while, without exogenously added antigen, the splenocytes of $\mathrm{TNF}^{-/-}$ hosts demonstrated a higher level of spontaneous pro-

\section{Figure 5}

( $\mathbf{a}$ and $\mathbf{b}$ ) Reconstitution of TNF- $\alpha$ in rBCG-infected TNF-/mice reduced the level of type 1 immune activation. $\mathrm{TNF}^{-/-}$ mice were injected intramuscularly and intranasally with an adenoviral TNF- $\alpha$ gene transfer vector (AdTNF) or a control vector (Addl) at the time of mycobacterial infection. At day 14, isolated splenocytes were subjected to ELISPOT assay to determine the relative frequency of mycobacterial antigen-specific $T$ cells (a) or an antigen stimulation assay to determine the level of IFN- $\gamma$ release (b). The difference between $\mathrm{TNF}^{-1-} /$ Addl and $\mathrm{TNF}^{-1-}$ AdTNF under M.tb CF stimulation conditions is statistically very significant $(P \leq 0.05)$. (c) Improved survival of $r B C G$ infected $\mathrm{TNF}^{-/-}$mice depleted of CD4 or CD8 or both $\mathrm{T}$ cells. CD 4 and CD8 T cells were depleted by 4 repeated injections of anti-CD4 and/or anti-CD8 monoclonal antibodies starting at 3 weeks after infection. Ten, seven, and seven $\mathrm{TNF}^{-/-}$mice received anti-CD4/CD8, anti-CD4 and anti-CD8 treatment, respectively. Eight $\mathrm{TNF}^{-/-}$mice were treated with normal rat IgG as control. (d) Reduced IFN- $\gamma$ levels in $\mathrm{TNF}^{-/-}$mice depleted of T cells. At day 37, several CD4/CD8 T cell-depleted TNF- ${ }^{-/-}\left(\mathrm{TNF}^{-/-} \mathrm{T}_{\text {cell }}{ }^{-/}\right)$and control mice were sacrificed. The level of IFN- $\gamma$ in blood and BAL fluids was evaluated. (e and $\mathbf{f}$ ) Lung histopathogy in control $\mathrm{TNF}^{-/-}$and $\mathrm{CD} 4 / \mathrm{CD} 8 \mathrm{~T}$ cell-depleted $\mathrm{TNF}^{-/-}$mice on day 37 after infection. The control $\mathrm{TNF}^{-/-}$lung underwent massive necrosis of both granuloma and lung structure (e). Note that part of the bronchus was also necrotic and filled with necrotic tissue and nucleic debris. The lung of $\mathrm{TNF}^{-/-}$ mice depleted of CD4/CD8 T cells contained largely intact granuloma with typical epithelioid cells $(\mathbf{f})$.

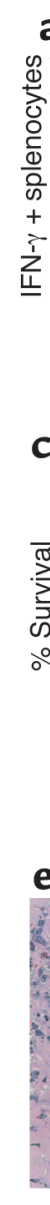
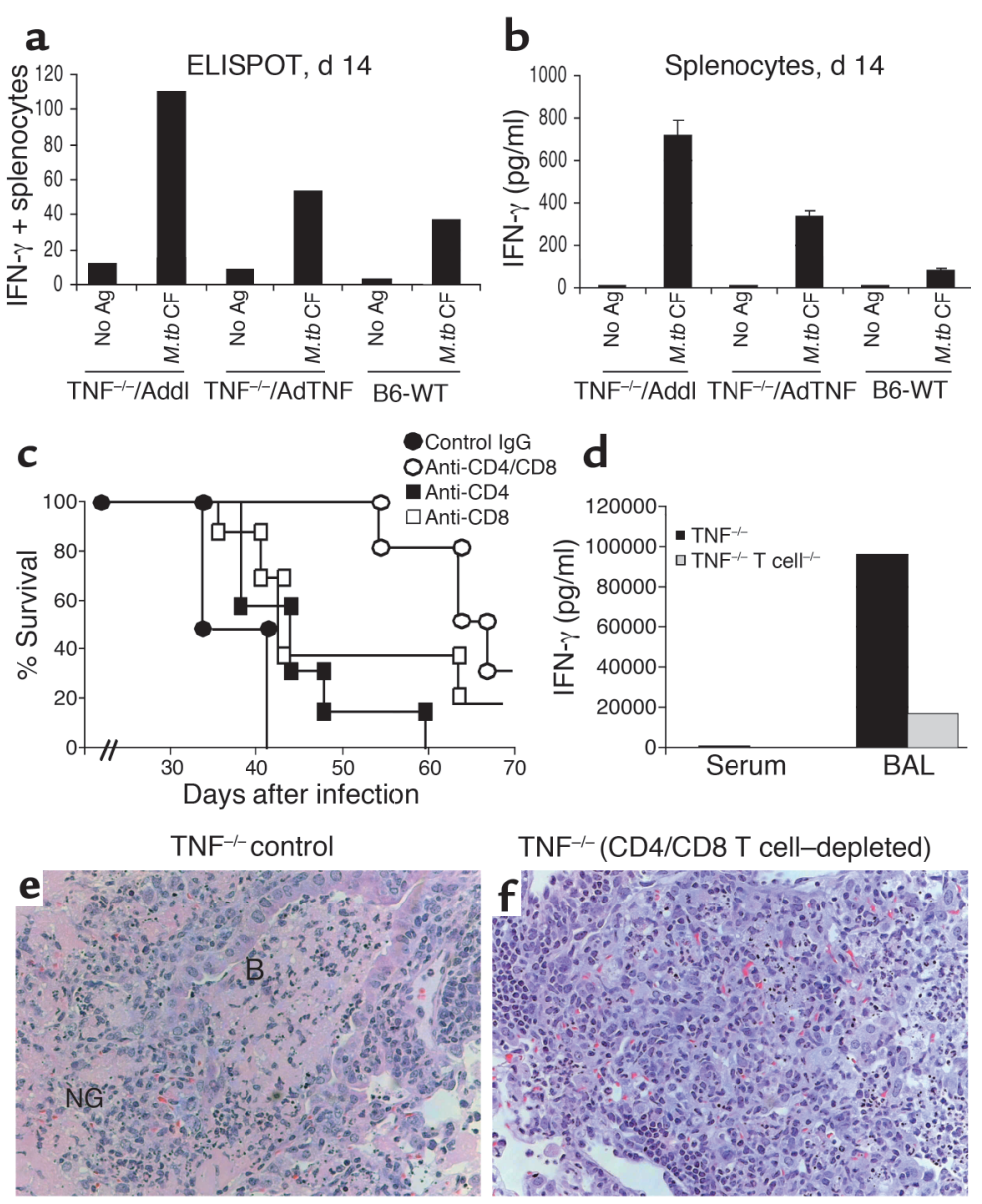

$\mathrm{TNF}^{-/}(\mathrm{CD} 4 / \mathrm{CD} 8 \mathrm{~T}$ cell-depleted $)$

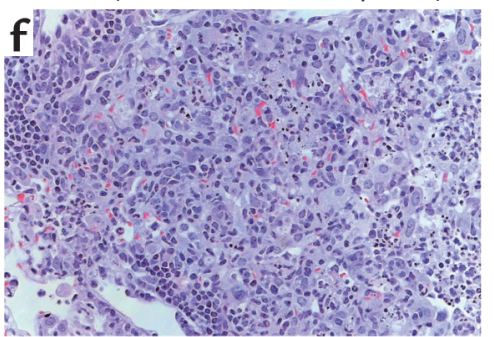



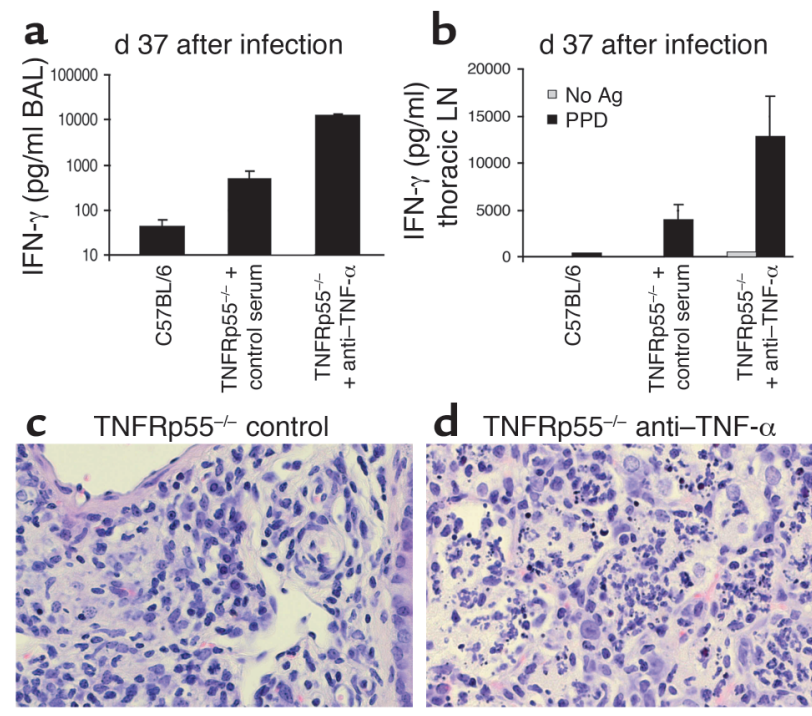

\section{Figure 6}

Role of TNFRp55 and p75-mediated signalling pathways in type 1 immune suppression by TNF- $\alpha$. TNFRp $55^{-/-}$mice were treated with anti-murine TNF serum or normal control serum at weeks 1,2 , and 3 after pulmonary $\mathrm{rBCG}$ mycobacterial infection. B6-WT mice were set up as controls. At day 37, mice were sacrificed and BAL fluids collected and measured for IFN- $\gamma(\mathbf{a})$. Isolated lymphoid cells were cultured with or without mycobacterial antigens (PPD) and culture supernatant measured for IFN- $\gamma$ by ELISA. PPD, purified protein derivatives (b). While the control TNFRp55/- mouse lung contained intact, mature granuloma (c), TNFRp 55/- mice treated with anti-TNF- $\alpha$ contained disintegrated granuloma in their lungs with many apoptotic cells (d).

liferation than those of their WT counterparts (Figure $8, \mathrm{~b}$ and $\mathrm{c}$ ), upon antigen stimulation, $\mathrm{TNF}^{-/-}$cells underwent a remarkably higher level of proliferation (Figure 8, $b$ and c). In vivo TNF- $\alpha$ gene transfer reduced not only heightened spontaneous proliferation but also antigen-stimulated proliferation (Figure $8, \mathrm{~b}$ and c), which coincided with markedly reduced IFN- $\gamma$ production by these cells (Figure 7, b and d). Since activated T cells of TNF-/- hosts released a lot more IFN- $\gamma$, we could not completely rule out the possibility that the heightened proliferation described above was due to the effect of IFN- $\gamma$ in an ex vivo culture system. Thus, CD4 $\mathrm{T}$ cells primed in vivo for 7 days by mycobacteria were purified from the spleens of $\mathrm{B} 6-\mathrm{WT}$ and $\mathrm{TNF}^{-/-}$ mice, labeled with CFSE, and adoptively transferred intravenously to sublethally $\gamma$-irradiated naive B6-WT and $\mathrm{TNF}^{-/}$mice. The homeostatic proliferative potential of these transferred CD4 T cells was subsequently analyzed and compared by FACS analysis. We found that about $50 \%$ of WT CD4 T cells did not undergo proliferation (stayed within the parental population) and $34 \%$ and $20 \%$ of them underwent one round and two rounds of proliferation, respectively (Figure 8d). This proliferative profile was entirely reversed in $\mathrm{TNF}^{-}-$CD 4 T cells: only $24 \%$ remained in the parental population, $28 \%$ underwent one round of proliferation, $42 \%$ underwent two rounds, and $4 \%$ underwent three rounds (Figure $8 \mathrm{~d}$ ). These results strongly suggest that
TNF- $\alpha$ controls the level of type 1 immunity by regulating the number of activated $\mathrm{T}$ cells.

\section{Discussion}

IL-12, IFN- $\gamma$, and TNF- $\alpha$ are among the type 1 cytokines crucial to type 1 immunity against intracellular pathogens including mycobacteria, listeria, and leishmania. While the role of IL-12 and IFN- $\gamma$ in antimicrobial type 1 immunity has been well defined as proimmune, the precise role of TNF- $\alpha$ has remained poorly understood. For instance, understanding of the role of TNF- $\alpha$ in antimycobacterial type 1 immunity has been restricted largely to the observation that infected $\mathrm{TNF}^{-/-}$hosts succumb to necrotic granuloma and heightened infection (5-11). Such observations, together with previous findings that TNF- $\alpha$ is a proinflammatory cytokine involved in cytokine cascade and leukocyte recruitment (1) and a proimmune cytokine required for IL-12 and IFN- $\gamma$ production $(33,34)$, Th1 polarization (34-36), and macrophage mycobactericidal activities (37-40), have led to the belief that TNF- $\alpha$ plays a proactive role in type 1 antimicrobial immunity by stimulating granuloma formation, type $1 \mathrm{~T}$ cell differentiation, and IFN- $\gamma$ production. However, this notion is confronted by several lines of independent observations. First, $\mathrm{TNF}^{-/-}$hosts tend to die sooner than IL-12-/- or IFN- $\gamma^{-/-}$counterparts after M.tb or BCG infection $(7,41,42)$. Second, IL-12/- mice that suffer diminished IFN- $\gamma$ and TNF- $\alpha$ responses and granuloma formation and heightened $M$. bovis BCG infection never succumb $(23,43)$. On the other hand, while SCID mice lack granuloma formation and have markedly diminished IL-12 and IFN- $\gamma$ responses, they rarely die with the level of heightened BCG infection that $\mathrm{TNF}^{-/}$ hosts die with (22). Of importance, regardless of high levels of mycobacterial infection in the lung of IL-12-/ (23) or $\operatorname{SCID}(22,25)$ mice, little apoptosis or necrosis of granuloma and lung tissue was detected. Third, $\mathrm{TNF}^{-/-}$mice appear normal or near normal in their ability to form macrophage granuloma. This suggests that these mice do not have a defect in cell recruitment and, rather, that they suffer from a problem that causes macrophage apoptosis and massive necrosis of granuloma and tissue structure. Together, these observations prompted us to postulate that quick death of $\mathrm{TNF}^{-/}$hosts was not due to infection per se but rather to yet poorly defined abnormalities underlying apoptosis and necrosis of tissue.

Indeed, our current study suggests the following: (a) Contrary to the previous belief that TNF- $\alpha$ is involved in Th1 polarization and type 1 cytokine responses (33-35), it is a negative regulator of type 1 immune activation, required for restricting the number of type $1 \mathrm{~T}$ cells, particularly Th1 cells, and subsequently the level of total IFN- $\gamma$ production. Thus, lack of TNF- $\alpha$-mediated immune-suppressive mechanisms results in a detrimental type 1 immune syndrome during infection by replicable mycobacteria, or dysregulated type 1 immune activation during host responses to infection by repli- 


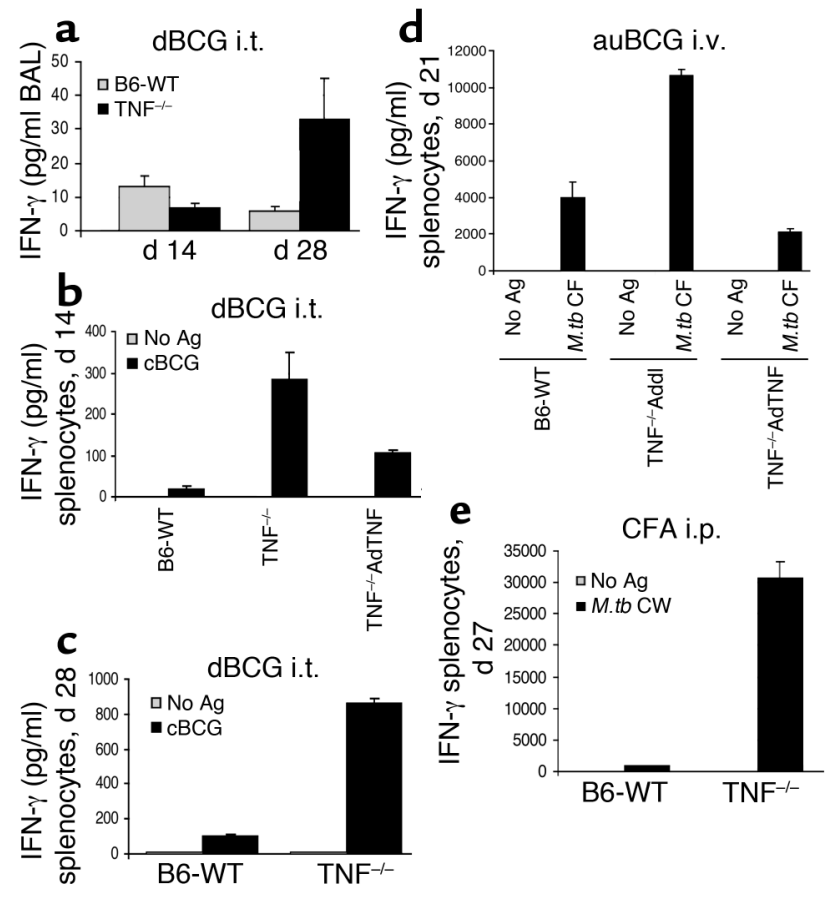

cation-deficient mycobacteria or exposure to dead mycobacteria or mycobacterial cell wall components (CFA). (b) TNF- $\alpha$ may not be critically required for granuloma formation. Instead, it helps to maintain the integrity of granuloma indirectly via its role in preventing immune overactivation. (c) Lack of TNF- $\alpha$ leads to overexpansion of type $1 \mathrm{CD} 4$ and CD8 $\mathrm{T}$ cells that cause granuloma disintegration, tissue destruction, and rapid death. (d) Thus, during intracellular bacterial infection, in addition to its role in macrophage activation, TNF- $\alpha$, via both TNFRp55-mediated and TNFRp75-mediated signaling, plays a critical immune-regulatory role in counterbalancing type $1 \mathrm{immune}$ activation and ameliorating potentially detrimental immunopathology. It is very unlikely that these findings result from the immune-developmental abnormalities that may be present in $\mathrm{TNF}^{-/-}$hosts. $\mathrm{TNF}^{-/-}$mice exhibited no developmental or morphologic abnormalities in any aspect of immune cells except that certain IgG responses were impaired (44). A number of published studies using TNF antibodies or other TNF antagonists in WT mice duplicated a fatal outcome seen in our $\mathrm{TNF}^{-/-}$model (6-9, 11, 45), and, in our current study, transient reconstitution of TNF- $\alpha$ transgene almost fully reverted the dysregulated immune phenotype, thus indicating a TNF- $\alpha$-specific phenomenon.

TNF- $\alpha$ possesses multiple proinflammatory activities, including induction of cytokines and activation of endothelial cells, macrophages, and neutrophils (1). TNF- $\alpha$ is also a key pathogenic player in endotoxic shock. In addition to its role in innate immune responses, TNF- $\alpha$ is ubiquitously induced during chronic host responses to intracellular pathogens. In this regard, TNF- $\alpha$, together with IL- 12 and IFN- $\gamma$, has long been classified as a type 1 immune cytokine $(3,46)$.

\section{Figure 7}

Role of TNF- $\alpha$ in type 1 immune responses to treatment with dead mycobacteria (dBCG; a-c) or to infection by live replication-deficient auxotrophic mycobacteria (auBCG; d) or to treatment with mycobacterial cell wall components (CFA; e). B6-WT or $\mathrm{TNF}^{-1-}$ mice were inoculated intratracheally (i.t.) with $\mathrm{dBCG}$. Some $\mathrm{TNF}^{-/-}$mice were also injected intramuscularly with a dose of AdTNF at the time of $d B C G$ administration. These mice were sacrificed at days 14 and 28. The level of IFN- $\gamma$ was measured by ELISA in the BAL fluids, and the results are expressed as mean \pm SEM from 4 mice per group (a) or culture supernatants of crude mycobacterial antigen (cBCG)-stimulated splenocytes isolated at days 14 (b) and 28 (c) after dBCG delivery. In some experiments, groups of $3 \mathrm{~B} 6-\mathrm{WT}$ and $\mathrm{TNF}^{-/-}$mice were infected i.v. with auBCG. Some TNF-/- were also injected with AdTNF or control vector Addl. The whole splenocytes were isolated and stimulated with mycobacterial antigens and culture supernatants measured for IFN- $\boldsymbol{\gamma}$ by ELISA (d). In other experiments, B6-WT and $\mathrm{TNF}^{-/-}$mice were injected intraperitoneally (i.p.) with complete Freund's adjuvant (CFA). The whole splenocytes were isolated at day 27 and stimulated with M.tb cell wall antigens (M.tb CW) and culture supernatants measured for IFN- $\gamma$ by ELISA (e).

However, in contrast to the tight regulation of IL-12 or IFN- $\gamma$ expression, TNF- $\alpha$ was quickly released independent of other type 1 cytokines in the course of mycobacterial infection $(26,47)$. The requirement of TNF- $\alpha$ in adaptive immune responses to mycobacterial infection was first unequivocally demonstrated in a study where administration of anti-TNF- $\alpha$ antibodies resulted in disintegration of granuloma and weakened host defense against M. bovis BCG infection (5). Thereafter, many other laboratories also observed, using $\mathrm{TNF}^{-/-}$mice $(6,9,10,48-50)$, antibodies (6), or TNF- $\alpha$ antagonist (7), that lack of TNF- $\alpha$ led to necrotic granuloma and weakened host defense against $M$. bovis BCG or M.tb infection. Furthermore, the host that lacked TNF- $\alpha$ was even more susceptible than the one that lacked IFN- $\gamma(7,41)$. Recently, TNF- $\alpha$ neutralization was also found to lead to fatal reactivation of persistent M.tb infection, which appeared to be associated with severe lung pathology but not with only moderately increased infection (45). The requirement of TNF- $\alpha$ for optimal granulomatous responses and host defense against mycobacterial infection was also demonstrated in mouse models lacking TNFRp55 (TNFRI) $(6,8,11)$. However, while the requirement of TNF- $\alpha$ for antimicrobial type 1 immunity has been widely observed, its precise role has remained poorly understood. In particular, little is known about whether and how TNF- $\alpha$ is involved in the regulation of development of type 1 immunity and T cell activation, how the functions of TNF- $\alpha$ relate to formation and/or maintenance of macrophage granuloma, and what is the relationship among $T$ cell activation, granuloma integrity, and death of the host.

Our current study has provided, for the first time to our knowledge, unequivocal evidence that TNF- $\alpha$ is a 

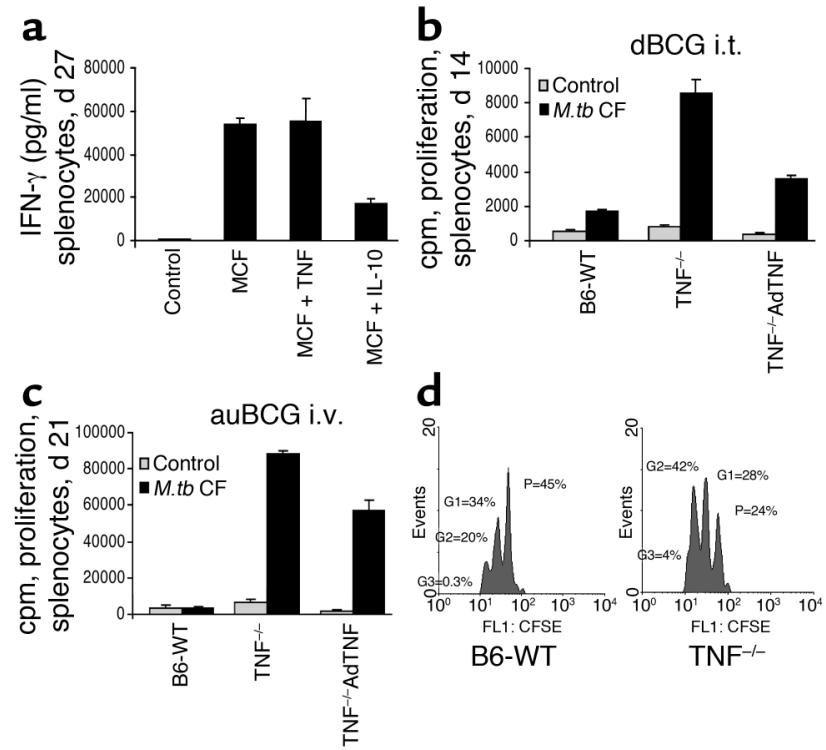

\section{Figure 8}

Mechanisms by which TNF- $\alpha$ controls type 1 immune activation. Splenocytes were isolated from rBCG-infected $\mathrm{TNF}^{-/-}$mice and cultured without (control) or with mycobacterial antigens (M.tb CF) in the presence or absence of recombinant murine TNF- $\alpha$ or IL-10. Culture supernatants were measured for $\operatorname{IFN}-\gamma(\mathbf{a})$. In separate experiments, splenocytes were isolated from B6-WT and $\mathrm{TNF}^{-/-}$mice treated intratracheally with dBCG (b) or i.v. with auBCG (c) at the specified time. Some $\mathrm{TNF}^{-/-}$mice were also injected intramuscularly with AdTNF at the time of dBCG administration or auBCG infection. These cells were cultured for 3 days with or without mycobacterial antigen stimulation (M.tb CF). ${ }^{3} \mathrm{H}$-thymidine was added to cells in the last 18 hours of culture. Cell proliferation was measured on a $\beta$ counter. To measure $T$ cell proliferation in vivo, mycobacteriumprimed splenic CD4 T cells were purified from B6-WT and $\mathrm{TNF}^{-1-}$ mice, labelled with CFSE and adoptively transferred i.v. to $\gamma$-irradiated naive B6-WT and $\mathrm{TNF}^{-/-}$mice, respectively. Total splenocytes were then isolated from these mice eight days after cell transfer, and the proliferative profile of transferred CFSE-labelled CD4 T cells were analyzed by FACS (d). P, parental population; G1, generation 1 (cells that have undergone one round of proliferation in vivo).

critical negative regulator of type 1 immune activation during intracellular mycobacterial infection. Prior to our study, a number of previous studies involving models of intracellular infection presented clues concerning the anti-inflammatory/immune property of this cytokine. $\mathrm{TNF}^{-/}$mice mysteriously developed an intense, "disorganized" tissue-inflammatory response and succumbed to challenge with heat-killed Corynebacterium parvum (44), which was later found to be associated with elevated circulating IL-12 (51). In a model of leishmaniasis, lymphocytes of $\mathrm{TNF}^{-/}$mice released more IFN- $\gamma$ than those of WT controls at day 18 after infection (52). Heightened chemokine responses were also found in the lung of M. bovis BCG-infected TNF-/mice (49). Persistent expression of proinflammatory mediators including IL- 1 and IL-18 and heightened tissue inflammation were also found in the lung of M.tbinfected mice with lung-specific TNF- $\alpha$ deficiency (50). Mycobacterium avium-infected mice lacking TNFRp55 had increased type 1 cytokine levels in plasma and tissue homogenates prior to death (11). Furthermore, there is also increasing evidence from both human and experimental studies that the immunosuppressive property of TNF- $\alpha$ is required for control of the level of autoimmune responses (15-17). In our current study, we have provided evidence that TNF- $\alpha$ controls the level of antibacterial type 1 immune activation, primarily by limiting the proliferation of antigen-specific type $1 \mathrm{~T}$ cells, particularly Th1 cells. Such immune-suppressive functions of TNF- $\alpha$ begin to be required from the early stage of type 1 immune activation. We found that in the absence of TNF- $\alpha$, T cell proliferation and the number of antigen-specific type $1 \mathrm{~T}$ cells were already markedly increased by day 14, when the level of infection was similar between $\mathrm{B} 6-\mathrm{WT}$ and $\mathrm{TNF}^{-/-}$mice and when little activation was discerned in WT controls. The early requirement of the immune-suppressive property of TNF- $\alpha$ for counterbalance of immune activation is apparently well met by its early abundant expression in macrophages and dendritic cells upon infection, and therefore other regulatory molecules are not required for such expression $(26,47)$. Control by TNF- $\alpha$ of type 1 immune activation via limitation of $T$ cell proliferation does not seem to be restricted only to intracellular bacterial infection, since TNF- $\alpha$ has been shown in an autoimmunity model to directly suppress Th cell proliferation and activation by attenuating TCR signaling $(53,54)$.

In our study, we have also established a causal link between overactivation of type 1 immunity and tissue destruction and death in $\mathrm{TNF}^{-/-}$hosts infected by replicable mycobacteria by depleting $\mathrm{T}$ cells with monoclonal antibodies. Depletion of both CD4 and CD8 T cells markedly decreased the level of IFN- $\gamma$ production, prevented granuloma disintegration and lung tissue injury, and prolonged survival without affecting the level of infection. However, depletion of either CD4 or CD8 T cells only moderately improved the survival of these mice. Since CD4 T cells were found to be a greater source of IFN- $\gamma$ than CD8 T cells, it is likely that both IFN- $\gamma$ and $\mathrm{T}$ cell-mediated cytotoxicity were responsible for macrophage apoptosis and tissue destruction in this model. Indeed, IFN- $\gamma$ was shown to induce apoptosis of monocytic cells in vitro $(55,56)$, and high levels of this cytokine were also associated with a high level of apoptosis and tissue immunopathology in vivo during intracellular infection (57). Caseous necrosis in human tuberculosis was also recently found to be associated with enhanced IFN- $\gamma$ and apoptosis $(58,59)$. It is important to point out that the nature and regulation of immune responses in human TB could be more complicated than what we have learned from our current model system. In this regard, there are also reports that link decreased TNF- $\alpha$ and increased IFN- $\gamma$ with improved clinical presentation $(60,61)$. Overproduction of TNF- $\alpha$ may also lead to unwanted histopathology (46).

The immune-suppressive role of TNF- $\alpha$ during mycobacterial infection was further consolidated in our 
models in which heat-inactivated or live replication-deficient mycobacteria or mycobacterial cell wall components (CFA) were used. Although no longer succumbing to ongoing immune responses, $\mathrm{TNF}^{-/-}$hosts still displayed heightened type 1 immune activation when the level of mycobacterial antigens or infection was set to be identical or similar to that in WT control mice, whereas TNF- $\alpha$ gene transfer brought the level of immune activation back close to normal. A lethal type 1 immune syndrome does not develop unless $\mathrm{TNF}^{-/}$- hosts are exposed to replicable mycobacteria, most likely because of a vicious combination of uncontrollable mycobacterial replication, antigen overloading, and lack of critical immune-suppressive mechanisms mediated by TNF- $\alpha$. The importance and potency of such TNF- $\alpha$-mediated immune regulation is further highlighted by findings that heightened mycobacterial infection in mice deficient in IL-18, IL-1, or IL-6 failed to uplift the level of type 1 immune responses, since such cytokine-deficient mice suffered diminished type 1 activation (62-64). We believe that our findings call for a rethinking of the role of TNF- $\alpha$ in type 1 immune activation. Given the indispensable role of TNF- $\alpha$ in control of the level of type 1 immune activation, a partial, rather than a complete, TNF- $\alpha$ blockade should be considered for anti-TNF- $\alpha$ therapy designed to treat type 1 immune conditions.

\section{Acknowledgments}

This study was supported by grants from the Canadian Institutes of Health Research. The authors wish to express their gratitude for the construction of the adenoviral TNF- $\alpha$ gene vector by Bob Marr and invaluable technical assistance provided by Mary Jo Smith, Jennifer Wattie, Kelly Dayball, Duncan Chong, Xueya Feng, Naoko Aoki, and Xizhong Zhang.

1. McDermott, M.F. 2001. TNF and TNFR biology in health and disease. Cell. Mol. Biol. 47:619-635.

2. Standiford, T.J. 2000. Anti-inflammatory cytokines and cytokine antagonists. Curr. Pharm. Des. 6:633-649.

3. Kaplan, G., and Freedman, V.H. 1997. The role of cytokines in the immune response to tuberculosis. Res. Immunol. 147:565-572.

4. Keane, J., et al. 2001. Tuberculosis associated with infliximab, a tumor necrosis factor alpha-neutralizing agent. N. Engl. J. Med. 345:1098-1104.

5. Kindler, V., Sappino, A.P., Grau, G.E., Piguet, P.F., and Vassalli, P. 1989. The inducing role of tumor necrosis factor in the development of bactericidal granulomas during BCG infection. Cell. 56:731-740.

6. Flynn, J.L., et al. 1995. Tumor necrosis factor-alpha is required in the protective immune response against Mycobacterium tuberculosis in mice. Immunity. 2:561-572

7. Garcia, I., Miyazaki, Y., Marchal, G., Lesslauer, W., and Vassalli, P. 1997. High sensitivity of transgenic mice expressing soluble TNFR1 fusion protein to mycobacterial infections: synergistic action of TNF and IFN-gamma in the differentiation of protective granulomas. Eur. J. Immunol. 27:3182-3190.

8. Senaldi, G., et al. 1996. Corynebacterium parvum- and Mycobacterium bovis bacillus Calmette-Guerin-induced granuloma formation is inhibited in TNF receptor I (TNF-RI) knockout mice and by treatment with soluble TNF-RI. J. Immunol. 157:5022-5026.

9. Kaneko, H., et al. 1999. Role of tumor necrosis factor-alpha in Mycobacterium-induced granuloma formation in tumor necrosis factor-alphadeficient mice. Lab. Invest. 79:379-386.

10. Bean, A.G., et al. 1999. Structural deficiencies in granuloma formation in TNF gene-targeted mice underlie the heightened susceptibility to aerosol Mycobacterium tuberculosis infection, which is not compensated for by lymphotoxin. J. Immunol. 162:3504-3511.

11. Ehlers, S., et al. 1999. Fatal granuloma necrosis without exacerbated mycobacterial growth in tumor necrosis factor receptor p55 gene-defi- cient mice intravenously infected with Mycobacterium avium. Infect. Immun. 67:3571-3579.

12. Roach, D.R., et al. 2002. TNF regulates chemokine induction essential for cell recruitment, granuloma formation, and clearance of mycobacterial infection. J. Immunol. 168:4620-4627.

13. Liu, J., et al. 1998. TNF is a potent anti-inflammatory cytokine in autoimmune-mediated demyelination. Nat. Med. 4:78-83.

14. Kassiotis, G., and Kollias, G. 2001. Uncoupling the proinflammatory from the immunosuppressive properties of TNF at the p55 TNF receptor level: implications for pathogenesis and therapy of autoimmune demyelination. J. Exp. Med. 193:427-434.

15. Campbell, I.K., O’Donnell, K., Lawlor, K.E., and Wicks, I.P. 2001. Severe inflammatory arthritis and lymphoadenopathy in the absence of TNF. J. Clin. Invest. 107:1519-1527.

16. van Oosten, B.W., et al. 1996. Increased MRI activity and immune activation in two multiple sclerosis patients treated with the monoclonal anti-TNF antibody cA2. Neurology. 47:1531-1534.

17. Sandborn, W.J., and Hanauer, S.B. 1999. Anti-tumor necrosis factor therapy for inflammatory bowel disease: a review of agents, pharmacology, clinical results and safety. Inflamm. Bowel Dis. 5:119-133.

18. Pfeffer, K., et al. 1993. Mice deficient for the $55 \mathrm{kd}$ tumor necrosis factor receptor are resistant to endotoxic shock, yet succumb to L. monocytogenes infection. Cell. 73:457-467.

19. Jackson, M., et al. 1999. Persistence and protective efficacy of a Mycobacterium tuberculosis auxotroph vaccine. Infect. Immun. 67:2867-2873.

20. Sime, P.J., et al. 1998. Transfer of TNF $\alpha$ gene to rat lung induces sever pulmonary inflammation and patchy interstitial fibrogenesis with induction of TGF beta1 and myofibroblasts. Am. J. Pathol. 153:825-832.

21. Xing, Z., Ohkawara, Y., Jordana, M., Graham, F.L., and Gauldie, J. 1996. Transfer of granulocyte-macrophage colony-stimulating factor gene to rat lung induces eosinophilia, monocytosis, and fibrotic reactions. J. Clin. Invest. 97:1102-1110.

22. Xing, Z., Zganiacz, A., Wang, J., and Sharma, S.K. 2001. Enhanced protection against fatal mycobacterial infection in SCID beige mice by reshaping innate immunity with IFN- $\gamma$ transgene. J. Immunol. 167:375-383

23. Wakeham, J., et al. 1998. Lack of both types 1 and 2 cytokines, tissue inflammatory responses and immune protection during pulmonary infection by Mycobacterium bovis BCG in IL-12 deficient mice.J. Immunol. 160:6101-1611.

24. Xing, Z., Zganiacz, A., Wang, J., Divangahi, M., and Nawaz, F. 2000. IL-12independent Th1-type immune responses to respiratory viral infection requirement of IL-18 for IFN- $\gamma$ release in the lung but not for the differentiation of viral-reactive Th1-type lymphocytes. J. Immunol. 164:2575-2584.

25. Xing, Z., Wang, J., Croitoru, K., and Wakeham, J. 1998. Protection by CD4 or CD8 T cells against pulmonary Mycobacterium bovis Bacillus Calmette-Guérin infection. Infect. Immun. 66:5537-5542.

26. Wang, J., Wakeham, J., Harkness, R., and Xing, Z. 1999. Macrophages are a significant source of type 1 cytokines during mycobacterial infection. J. Clin. Invest. 103:1023-1029.

27. Wang, J., et al. 2000. Transgenic expression of GM-CSF induces the differentiation and activation of a novel dendritic cell population in the lung. Blood. 95:2337-2345

28. Xing, Z., Ohkawara, Y., Jordana, M., Graham, F.L., and Gauldie, J. 1997. Adenoviral vector-mediated IL-10 expression in vivo: intramuscular gene transfer inhibits cytokine responses in endotoxemia. Gene Ther 4:140-149.

29. Santosuosso, M., Divangahi, M., Zganiacz, A., and Xing, Z. 2002. Reduced tissue macrophage population in the lung by anti-cancer agent cyclophosphamide: restoration by local GM-CSF gene transfer. Blood. 99:1246-1252.

30. Grayson, J.M., Harrington, L.E., Lanier, J.G., Wherry, E.J., and Ahmed, R. 2002. Differential sensitivity of naïve and memory CD8 T cells to apoptosis in vivo. J. Immunol. 169:3760-3770.

31. Inman, M.D., Ellis, R., Wattie, J., Denburg, J.A., and O’Byrne, P.M. 1999. Allergen-induced increases in airway responsiveness, airway eosinophilia and bone marrow eosinophil progenitors in mice. Am. J. Respir. Cell Mol. Biol. 21:473-479.

32. Fu, Y.-X., et al. 1994. Immune protection and control of inflammatory tissue necrosis by gamma/delta T cells. J. Immunol. 153:3101-3109.

33. Flesch, I.E., et al. 1995. Early interleukin 12 production by macrophages in response to mycobacterial infection depends on interferon gamma and tumor necrosis factor alpha. J. Exp. Med. 181:1615-1621.

34. Becher, B., Blain, M., Giacomini, P.S., and Antel, J.P. 1999. Inhibition of Th1 polarization by soluble TNF receptor is dependent on antigen-presenting cell-derived IL-12. J. Immunol. 162:684-688.

35. Ahlers, J.D., Belyakov, I.M., Matsui, S., and Berzofsky, J.A. 2001. Signals delivered through TCR instruct IL-12 receptor (IL-12R) expression: IL-12 and tumor necrosis factor-alpha synergize for IL-12R expression at low antigen dose. Int. Immunol. 13:1433-1442.

36. Shibuya, K., et al. 1998. IL-1 alpha and TNF-alpha are required for 
IL-12-induced development of Th1 cells producing high levels of IFNgamma in BALB/c but not C57BL/6 mice. J. Immunol. 160:1708-1716.

37. Hirsch, C.S., Ellner J.J., Russel D.G., and Rich, E.A. 1994. Complement receptor-mediated uptake and tumor necrosis factor-alpha-mediated growth inhibition of Mycobacterium tuberculosis by human alveolar macrophages. J. Immunol. 152:743-753.

38. Sato, K., Akaki, T., and Tomioka, H. 1998. Differential potentiation of anti-mycobacterial activity and reactive nitrogen intermediate-producing ability of murine peritoneal macrophages activated by IFN-gamma and TNF-alpha. Clin. Exp. Immunol. 112:63-68.

39. Bermudez, L.E.M., and Young, L.S. 1988. TNF, alone or in combination with IL-2, but not IFN gamma, is associated with macrophage killing of M. avium complex. J. Immunol. 140:3006-3013.

40. Bekker, L., Freeman, S., Murray, P.J., Ryffel, B., and Kaplan, G. 2001 TNF-alpha controls intracellular mycobacterial growth by both inducible nitric oxide synthase-dependent and inducible nitric oxide synthase-independent pathways. J. Immunol. 166:6728-6734.

41. Kamijo, R., et al. 1993. Mice that lack the IFN-gamma receptor have profoundly altered responses to infection with BCG and subsequent challenge with LPS. J. Exp. Med. 178:1435-1440.

42. Cooper, A.M., et al. 1993. Disseminated tuberculosis in IFN-gamma gene-disrupted mice. J. Exp. Med. 178:2243-2248.

43. Holscher, C., et al. 2001. A protective and agonistic function of IL-12p40 in mycobacterial infection. J. Immunol. 167:6957-6966.

44. Marino, M.W., et al. 1997. Characterization of TNF-deficient mice. Proc. Natl. Acad. Sci. U. S. A. 94:8093-8098.

45. Mohan, V.P., et al. 2001. Effects of tumor necrosis factor alpha on host immune response in chronic persistent tuberculosis: possible role for limiting pathology. Infect. Immun. 69:1847-1855.

46. Xing, Z. 2001. The hunt for new tuberculosis vaccines: anti-TB immunity and rational design of vaccine. Curr. Pharm. Des. 7:1015-1037.

47. Xing, Z., Zganiacz, A., and Santosuosso, M. 2000. Role of IL-12 in macrophage activation during intracellular infection: IL-12 and mycobacteria synergistically release TNF- $\alpha$ and nitric oxide from macrophages via IFN- $\gamma$ induction. J. Lenkoc. Biol. 68:897-902.

48. Bekker, L., et al. 2000. Immunopathologic effects of TNF alpha in murine mycobacterial infection are dose dependent. Infect. Immun. 68:6954-6961.

49. Olleros, M.L., et al. 2002. Transmembrane TNF induces an efficient cellmediated immunity and resistance to $\mathrm{M}$. bovis BCG infection in the absence of secreted TNF and lymphotoxin-alpha. J. Immunol. 168:3394-3401.
50. Smith, S., et al. 2002. Local role for tumor necrosis factor alpha in the pulmonary inflammatory response to Mycobacterium tuberculosis infection. Infect. Immun. 70:2082-2089.

51. Hodge-Dufour, J., et al. 1998. Inhibition of IFN gamma induced IL-12 production: a potential mechanism for the anti-inflammatory activities of TNF. Proc. Natl. Acad. Sci. U. S. A. 95:13806-13811.

52. Wilhelm, P., et al. 2001. Rapidly fatal leishmaniasis in resistant C57BL/6 mice lacking TNF. J. Immunol. 166:4012-4019.

53. Cope, A.P. 1998. Regulation of autoimmunity by proinflammatory cytokines. Curr. Opin. Immunol. 10:669-676.

54. Cope, A.P., et al. 1997. Chronic TNF alters T cell responses by attenuating T cell receptor signaling. J. Exp. Med. 185:1573-1584.

55. Lopez-Collazo, E., Hortelano, S., and Bosca, L. 1998. Interferonalpha/beta inhibits the apoptosis induced by lipopolysaccharide and interferon-gamma in murine peritoneal macrophages. J. Interferon Cytokine Res. 18:461-467.

56. Hortelano, S., Castrillo, A., Alvarez, A.M., and Bosca, L. 2000. Contribution of cyclopentenone prostaglandins to the resolution of inflammation through the potentiation of apoptosis in activated macrophages. J. Immunol. 165:6525-6531.

57. Gavrilescu, L.C., and Denkers, E.Y. 2001. IFN-gamma overproduction and high level apoptosis are associated with high but not low virulence Toxoplasma gondii infection. J. Immunol. 167:902-909.

58. Hirsch, C.S., et al. 2001. Augmentation of apoptosis and interferongamma production at sites of active Mycobacterium tuberculosis infection in human tuberculosis. J. Infect. Dis. 183:779-788.

59. Fayyazi, A., et al. 2000. Apoptosis of macrophages and T cells in tuberculosis associated caseous necrosis. J. Pathol. 191:417-425.

60. Condos, R., Rom, W.N., Liu, Y.M., and Schluger, N.W. 1998. Local immune responses correlate with presentation and outcome in tuberculosis. Am. J. Respir. Crit. Care Med. 157:729-735.

61. Tramontana, J.M., et al. 1995. Thalidomide treatment reduces tumor necrosis factor alpha production and enhances weight gain in patients with pulmonary tuberculosis. Mol. Med. 1:384-397.

62. Sugawara, I., et al. 1999. Role of IL-18 in mycobacterial infection in IL-18gene disrupted mice. Infect. Immun. 67:2585-2589.

63. Juffermans, N.P., et al. 2000. IL-1 signaling is essential for host defense during murine pulmonary tuberculosis. J. Infect. Dis. 182:902-908.

64. Saunders, B.M., Frank, A.A., Orme, I.M., and Cooper, A.M. 2000. Interleukin- 6 induces early gamma interferon production in the infected lung but is not required for generation of specific immunity to Mycobacterium tuberculosis infection. Infect. Immun. 68:3322-3326. 